\title{
BMJ Open Provision of critical care for the elderly in Europe: a retrospective comparison of national healthcare frameworks in intensive care units
}

\begin{abstract}
Bernhard Wernly (D) , ${ }^{1,2}$ Michael Beil, ${ }^{3}$ Raphael Romano Bruno (D) ${ }^{4}$ Stephan Binnebössel, ${ }^{4}$ Malte Kelm (1) , ${ }^{4}$ Sviri Sigal, ${ }^{3}$ Peter Vernon van Heerden, ${ }^{5}$ Ariane Boumendil, ${ }^{6}$ Antonio Artigas, ${ }^{7}$ Maurizio Cecconi, ${ }^{8}$ Brian Marsh, ${ }^{9}$ Rui Moreno, ${ }^{10}$ Sandra Oeyen, ${ }^{11}$ Bernardo Bollen Pinto, ${ }^{12}$ Wojciech Szczeklik (D),${ }^{13}$ Susannah Leaver, ${ }^{14}$ Sten Mikael Walther, ${ }^{15,16}$ Joerg C Schefold, ${ }^{17}$ Michael Joannidis, ${ }^{18}$ Jesper Fjølner, ${ }^{19}$ Tilemachos Zafeiridis, ${ }^{20}$ Dylan de Lange, ${ }^{21}$ Bertrand Guidet, ${ }^{22}$ Hans Flaatten, ${ }^{23}$ Christian Jung, ${ }^{4}$ On behalf of the VIP2 study group
\end{abstract}

To cite: Wernly B, Beil M, Bruno RR, et al. Provision of critical care for the elderly in Europe: a retrospective comparison of national healthcare frameworks in intensive care units. BMJ Open 2021;11:e046909. doi:10.1136/ bmjopen-2020-046909

- Prepublication history and additional supplemental material for this paper are available online. To view these files, please visit the journal online (http://dx.doi.org/10.1136/ bmjopen-2020-046909).

Received 20 November 2020 Accepted 13 May 2021

Deck for updates

(c) Author(s) (or their employer(s)) 2021. Re-use permitted under CC BY-NC. No commercial re-use. See rights and permissions. Published by BMJ.

For numbered affiliations see end of article.

Correspondence to Dr Christian Jung; christian.jung@med.uniduesseldorf.de

\section{ABSTRACT}

Objectives In Europe, there is a distinction between two different healthcare organisation systems, the tax-based healthcare system (THS) and the social health insurance system (SHI). Our aim was to investigate whether the characteristics, treatment and mortality of older, critically ill patients in the intensive care unit (ICU) differed between THS and SHI.

Setting ICUs in 16 European countries.

Participants In total, 7817 critically ill older ( $\geq 80$ years) patients were included in this study, 4941 in THS and 2876 in the SHI systems.

Primary and secondary outcomes measures We chose generalised estimation equations with robust standard errors to produce population average adjusted OR (aOR). We adjusted for patient-specific variables, health economic data, including gross domestic product (GDP) and human development index (HDI), and treatment strategies.

Results In SHI systems, there were higher rates of frail patients (Clinical Frailty Scale $>4 ; 46 \%$ vs $41 \%$; $p<0.001$ ), longer length of ICU stays $(90 \pm 162$ vs $72 \pm 134$ hours; $p<0.001)$ and increased levels of organ support. The ICU mortality (aOR 1.50, 95\% Cl 1.09 to 2.06; $p=0.01$ ) was consistently higher in the SHl; however, the 30-day mortality (aOR $0.89,95 \% \mathrm{Cl} 0.66$ to $1.21 ; \mathrm{p}=0.47$ ) was similar between THS and SHI. In a sensitivity analysis stratifying for the health economic data, the 30-day mortality was higher in SHI, in low GDP per capita (aOR $2.17,95 \% \mathrm{Cl} 1.42$ to 3.58 ) and low $\mathrm{HDI}(\mathrm{aOR} 1.22,95 \% \mathrm{Cl}$ 1.64 to 2.20 ) settings.

Conclusions The 30-day mortality was similar in both systems. Patients in SHI were older, sicker and frailer at baseline, which could be interpreted as a sign for a more liberal admission policy in SHI. We believe that the observed trend towards ICU excess mortality in SHI results mainly from a more liberal admission policy and an increase in treatment limitations.

Trial registration numbers NCT03134807 and NCT03370692.

\section{Strengths and limitations of this study}

We performed a retrospective post hoc analysis of a European cohort of critically ill patients who are 80 years and older.

- This study evaluated critically ill older ( $\geq 80$ years) patients, 4941 in tax-based healthcare system and 2876 in the social health insurance system systems from the VIP1 and VIP2 study.

- We compared baseline risk distribution using univariate methods according to the distribution.

- We compared management and mortality outcomes using generalised estimation equations with robust standard errors to produce population average adjusted aOR.

- We performed multiple sensitivity analyses stratifying 30-day mortality for patient-specific characteristics, treatment strategies and health economic data.

\section{INTRODUCTION}

Very old patients (often defined as being 80 years of age or older) admitted to an intensive care unit (ICU) have a high mortality. ${ }^{1}$ Whether this group of patients will benefit from intensive care treatment is the subject of clinical studies and ethical debate. ${ }^{23}$ Nevertheless, older patients consume a disproportionate amount of intensive care resources, with questionable benefits on morbidity and mortality, which raises both socioeconomic and ethical questions of sustainability. ${ }^{4-6}$

There are numerous factors that influence outcome, age being only one of many. ${ }^{7-9}$ In addition to the severity of organ dysfunction, the patient's functional and mental capacity prior to admission is of utmost importance. ${ }^{10}$ 
Multiple studies have confirmed the concept of frailty as a valuable tool, not only to assess the patient's prehospital condition, but also to predict outcome. ${ }^{11-14}$

In addition to patient-specific factors, specific healthcare system characteristics, such as availability of resources, are hypothesised to influence the outcome of critically ill older patients. ${ }^{15}$ In Europe, a rough distinction is made between two healthcare systems; the tax-based healthcare system (THS) and the social health insurance system (SHI). There are other more nuanced classification systems with higher granularity used to divide the organisation of healthcare systems. ${ }^{16-20}$ However, ultimately all subclassifications are variations of the initial subdivision into a primarily tax-financed, municipally organised system with a 'single payer' (THS) or into a social insurance system financed by predefined and earmarked premiums, mostly from payroll taxes, and organised in a more pluralistic way, often with the coexistence of both private and public service providers. ${ }^{21}$ A dichotomisation of the European healthcare system into THS versus SHI is therefore possibly an over-simplification, but it is nevertheless based on distinct differences. ${ }^{17}$ Other pragmatic analyses also use the same distinction, as well as the World Bank and the Organisation for European Economic Co-operation (OEEC). ${ }^{22}$ Differences in the treatment of older people between these two systems are likely, as the incentives for treating critically ill patients might differ between THS and SHI. In addition, differences in the way finances are allocated for elderly patients have been described. ${ }^{23}$

The VIP1 study evaluated 5021 critically ill patients over the age of 80 and showed that frailty assessed by the Clinical Frailty Scale (CFS) was associated with short-term mortality. The VIP2 study included acutely admitted 3920 critically ill patients over the age of 79 and confirmed the association of CFS with short-term mortality. ${ }^{1424}$

In this post hoc substudy of these two studies in very old intensive care patients (VIPs studies), we wanted to investigate whether the characteristics, management strategies (with a focus on organ support and treatment limitations) and mortality of older, critically ill patients in the ICU differed between THS and SHI. ${ }^{14}{ }^{24}$ Since older patients in particular have a high probability of death, even after survival of the initial intensive care stay, we have evaluated not only the ICU mortality but also the 30-day mortality. ${ }^{3}$ We hypothesised that patients differ significantly between THS and SHI with regards to baseline characteristics due to differing admission policies. Therefore, we speculated whether there were significant differences in the use of organ support and mortality rates between THS and SHI.

\section{METHODS}

\section{Study subjects}

VIP1 and VIP2 were prospective, multicentre studies, registered on ClinicalTrials.gov. ${ }^{1424}$ Both studies included very elderly VIPs, defined as patients aged 80 years or older. For VIP1, data were collected between October 2016 and
February 2017. For VIP2, VIPs were included from May 2018 to May 2019. Many countries could recruit patients without informed consent while some had to collect informed consent as the ethical consent procedures in Europe are diverse. For each patient baseline characteristics (including age, gender, main reason for admission and frailty) and management strategies (including use of renal replacement therapy (RRT), mechanical ventilation, non-invasive ventilation (NIV) and rates of use of vasoactive drugs) were documented. Also, any treatment limitations (treatment withheld, or treatment withdrawn) were documented.

In this post hoc analysis of these two prospective trials, all patients admitted acutely (ie, non-electively) with complete data on age, gender, Clinical Frailty Score (CFS) and Sequential Organ Failure Assessment (SOFA) Score and ICU mortality were included. ${ }^{9}$ Patients were defined as being in a THS (Denmark, Great Britain, Sweden, Norway, Ireland, Italy, Spain, Portugal and Greece; $\mathrm{n}=4941$ ) or SHI (Poland, Belgium, France, Germany, Netherlands, Austria and Switzerland; $n=2876$ ) healthcare system. We used the dichotomisation used by the World Bank and the OEEC. ${ }^{22}$ The primary endpoint of this study was ICU mortality, and the secondary endpoints were 30-day mortality and rates of treatment limitation. The data on 30-day mortality was available for only 7443 patients (THS n=4712; SHI n=2731). Frailty was assessed by the CFS and the respective visual and simple descriptions were used with permission. ${ }^{25-27}$ For the patients recruited to the VIP2 trial, Katz activities of daily living (Katz ADL) with ADL Score $\leq 4$ defining disability and short form of Informant Questionnaire on Cognitive Decline in the Elderly (IQCODE), with IQCODE $\geq 3.5$ describing cognitive decline and Co-morbidity and Polypharmacy Score were assessed..$^{25-27}$ The gross domestic product (GDP) per capita for 2019 in US $\$$ was retrieved from the International Money Fund, ${ }^{28}$ the human development index (HDI) from the United Nations Development Program, ${ }^{29}$ and the total (compulsory, voluntary, out-of-pocket) amount of health spending per capita in US\$ in 2019 from the Organisation for Economic Co-operation and Development. ${ }^{30}$ The number of ICU beds were obtained from a previous publication. ${ }^{31}$

\section{Patient and public involvement}

No patient involved.

\section{Statistical analysis}

We assessed continuous variables for distribution using Kolmogorov-Smirnov test. Normally distributed continuous data are given as mean $\pm \mathrm{SD}$ and compared using Student's t-test. Non-normally distributed continuous data are given as median $\pm \mathrm{IQR}$ and compared using Mann's U-test. Categorical data are given as numbers (percentage) and compared using the $\chi$ test.

The primary exposure was being in a THS versus SHI. The data are likely to be clustered on an ICU level. Therefore, a multilevel regression approach was chosen. As the health 


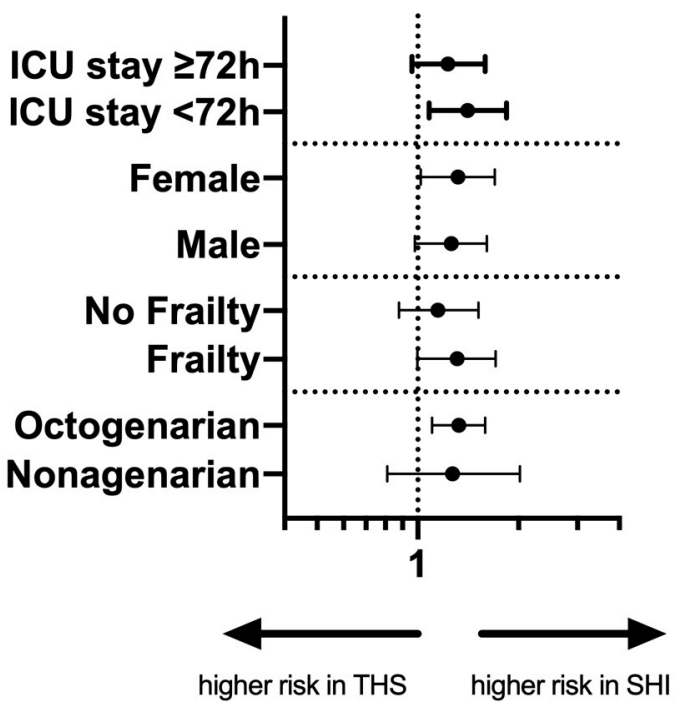

Figure 1 Sensitivity analyses stratifying 30-day mortality for patient-specific characteristics using generalised estimation equations producing population average ORs. The depicted aORs from model-1 include only the intensive care unit (ICU) as panel. The 30-day mortality was similar between taxbased healthcare system (THS) and health insurance system $(\mathrm{SHI})$ in male (aOR 1.26, 95\% Cl 0.98 to 1.61), frail (aOR 1.15, $95 \% \mathrm{Cl} 0.998$ to 1.710 ), non-frail (aOR $1.15,95 \% \mathrm{Cl} 0.88$ to 1.52), nonagenarian (aOR $1.27,95 \% \mathrm{Cl} 0.81$ to 2.02 ) patients. There was a higher mortality in $\mathrm{SHI}$ in octogenarian (aOR $1.29,95 \% \mathrm{Cl} 1.10$ to 1.59 ) and female (aOR $1.32,95 \% \mathrm{Cl} 1.02$ to 1.70$)$ patients and in patients staying below 72 hours (aOR $1.41,95 \% \mathrm{Cl} 1.08$ to 1.85$)$.

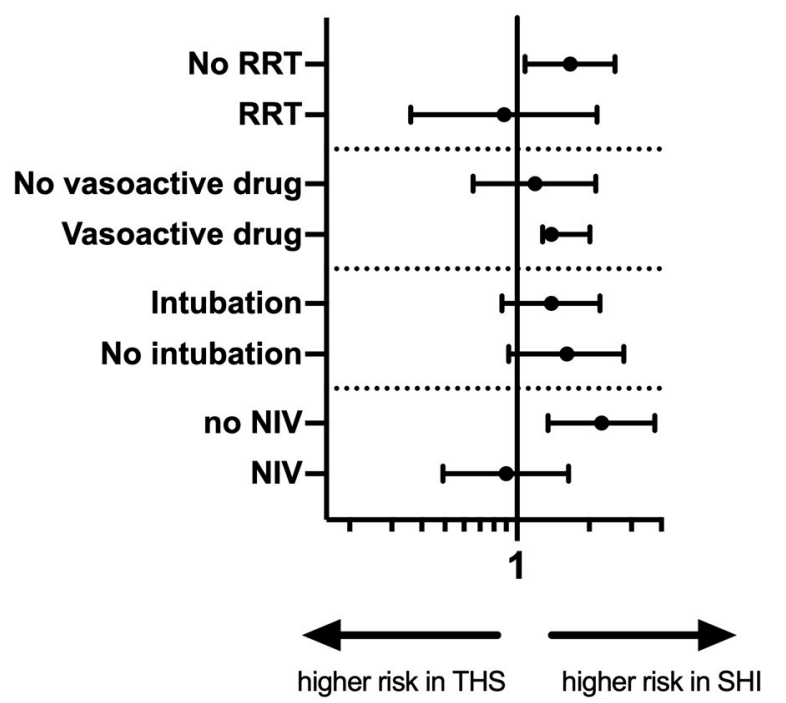

Figure 2 Sensitivity analyses stratifying 30-day mortality for treatment strategies using generalised estimation equations producing population average ORs. The depicted aORs from model-1 include only the intensive care unit as panel. The 30day mortality was similar in patients with renal replacement therapy (RRT), without vasoactive drugs, intubated and nonintubated paitents and patients on non-invasive ventilation (NIV). There was a trend towards higher 30-day mortality in patients without RRT (aOR 1.29, 95\% Cl 1.04 to 1.60) and without NIV (aOR $1.50,95 \% \mathrm{Cl} 1.16$ to 1.94). SHI, health insurance system; THS, tax-based healthcare system.

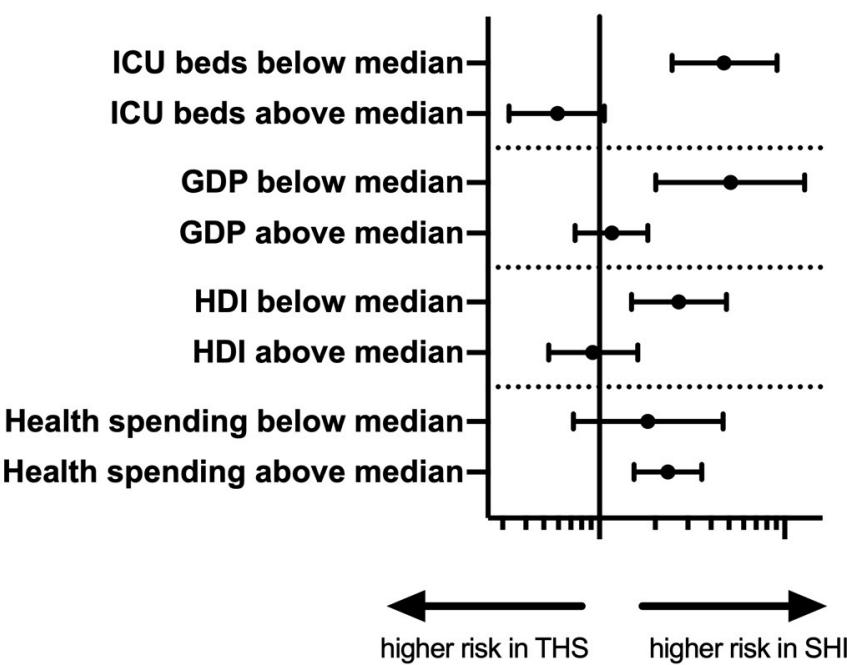

Figure 3 Sensitivity analyses stratifying 30-day mortality for health economic data using generalised estimation equations producing population average ORs. The depicted aORs from model-1 include only the intensive care unit (ICU) as panel. The 30-day-mortality was higher in SHI, in settings with low ICU beds per capita (aOR 2.17 95\% Cl 1.57-3.02), low gross domestic product (GDP) per capita (aOR $2.1795 \% \mathrm{Cl} 1.42-$ 3.58) and low human development index (HDI) (aOR 1.22 $95 \% \mathrm{Cl} 1.64-2.20)$, as well as in high total health spending settings. SHI, health insurance system; THS, tax-based healthcare system.

economic data do not vary within a given cluster, we chose generalised estimation equations (GEE) with robust standard errors to produce population average ORs. The survival analysis/GEE-based analyses were conducted using only robust estimators of the standard errors and not in the sense of robustness against violations of normality assumptions as for the robust methods (eg, Mann-Whitney tests) used for the univariate analyses. Model-1 includes only the ICU as panel. Model-2 includes patient specific factors (sex, age per year, SOFA Score per point, Frailty Score per CFS point and the admission diagnosis). Model-3 adds the health economic data (GDP per capita, HDI, health spending per capita and ICU beds per capita). Model- 4 adds the treatment strategies (treatment limitations and organ support) and calculates only mortality. Adjusted aOR and respective 95\% CI were obtained. Sensitivity analyses stratifying 30-day mortality for patient-specific characteristics (figure 1), treatment strategies (figure 2) and health economic data (figure 3) were done. Risk model calibration accuracy/goodness of fit was evaluated graphically by stratification of patients into SOFA quartiles and comparison of observed versus expected events within risk strata (figure 4 ). All tests were two sided, and a p value of $<0.05$ was considered statistically significant. Stata/IC V.16.1 was used for all statistical analyses.

\section{RESULTS}

Baseline risk distribution in SHI versus THS

In total, 7817 patients from 16 European countries were included in this study. The relative frequencies of the admission diagnoses varied between THS and SHI 


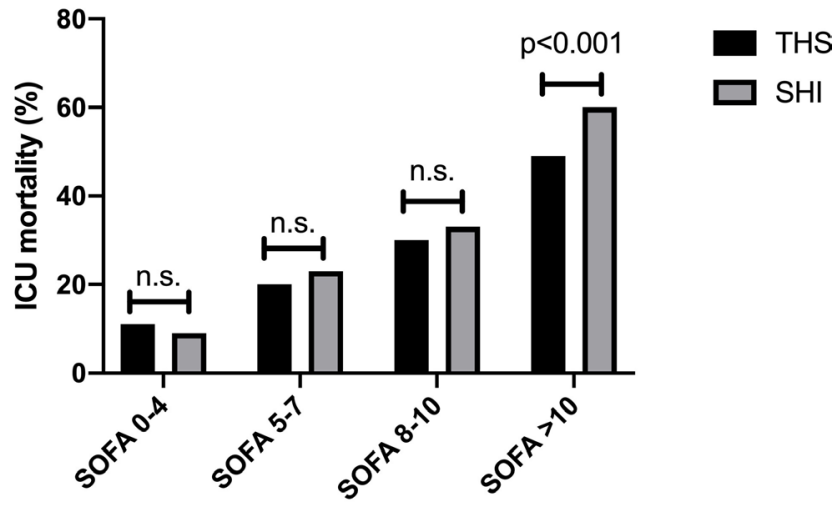

B

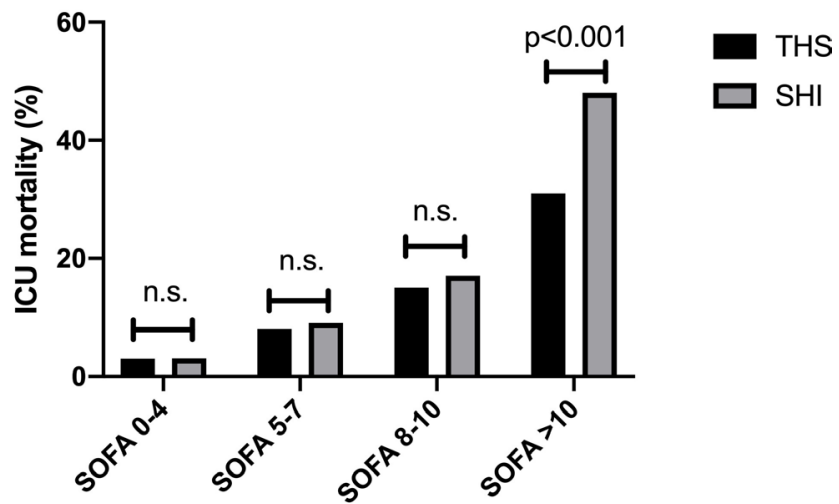

Figure 4 Risk model calibration accuracy/goodness of fit was evaluated graphically by stratification of patients into Sequential Organ Failure Assessment (SOFA) quartiles (Q1: SOFA 0-4; Q2:>4-7; Q3>7-10, Q4>10) and comparison of observed versus expected events within risk strata. In the graphical calibration analysis, both tax-based healthcare system (THS) and health insurance system (SHI) showed agreement of predicted intensive care unit (ICU) mortality probability and observed events in SOFA risk quartiles, both in all patients $(A)$ and in patients without any treatment limitation (B).

systems (table 1 ). There were higher rates of nonagenarians $(11 \%$ vs $9 \% ; \mathrm{p}=0.002)$ in SHI systems. The country specific differences within the systems are descriptively shown in online supplemental tables 1 and 2.

The rates of frail patients (CFS $>4 ; 46 \%$ vs $41 \%$; $\mathrm{p}<0.001$ ), as well as patients with disabilities (ADL $<5 ; 30 \%$ vs $24 \%$; $\mathrm{p}<0.001)$ ) and cognitive decline (IQCODE $\geq 3.5 ; 37 \%$ vs $29 \% ; \mathrm{p}<0.001)$, were higher in the SHI compared with THS. The length of ICU stay was higher $(90 \pm 162$ vs $72 \pm 134$ hours; $\mathrm{p}<0.001$ ) in the SHI (table 1$)$.

\section{Organ support and management in SHI versus THS}

The rates of NIV use were similar in model-1 and model-3 and showed a trend towards higher odds in the THS (table 2). The rates of RRT were consistently higher in the SHI in all models (table 2; model-3 aOR 1.89, 95\% CI 1.27 to $2.82 ; \mathrm{p}=0.002)$.

The crude rates for withholding treatment (34\% vs $26 \%$ ) were higher in SHI systems. This finding persisted in model-1 (aOR 1.44, 95\% CI 1.09 to $1.90 ; \mathrm{p}=0.01$ ) but not after adjustment for patient-specific variable in model-2 and after adjustment for the health economic data in model-3 (aOR 1.10, 95\% CI 0.78 to 1.53 ; $\mathrm{p}=0.59$; table 2).

\section{Mortality analysis}

The overall ICU mortality was $27 \%$ and the 30-day mortality was $41 \%$. The ICU mortality was consistently higher in the SHI systems, after adjustment for patientspecific variables in model-2, health economic data in model-3 and in model-4 integrating patient-specific data, health economic data as well as treatment strategies (aOR $1.5095 \%$ CI 1.09 to 2.06; $\mathrm{p}=0.01$ ). However, the 30-day mortality was similar between THS and SHI in all models (table 2).

\section{Sensitivity analyses}

In sensitivity analyses, stratifying 30-day mortality for patient-specific characteristics (figure 1), treatment strategies (figure 2) we observed no differences in 30-day mortality between THS and SHI, except for a trend towards higher mortality (aOR 1.41, 95\% CI 1.08 to 1.85 ) in patients staying below 72 hours in the ICU in SHI. However, in the sensitivity analyses stratifying for the health economic data (figure 3), the 30-day mortality was higher in SHI, in settings with a low number of ICU beds per capita (aOR 2.17, 95\% CI 1.57 to 3.02), low GDP per capita (aOR 2.17, 95\% CI 1.42 to 3.58 ) and low HDI (aOR $1.22,95 \%$ CI 1.64 to 2.20 ), as well as in high total health spending settings.

In the graphical calibration analysis both THS and SHI showed agreement for predicted ICU mortality probability and observed events in SOFA risk quartiles, both in all patients (figure 4A) and in patients without any treatment limitation (figure 4B).

\section{DISCUSSION}

The aim of our study was to investigate possible differences in the characteristics, management and outcome of VIPs between THS and SHI healthcare systems. In general, critically ill patients admitted to ICUs in SHI were older, frailer and more frequently suffered from cognitive impairment. All the health economic data, including the health spending per capita and the ICU beds available per capita, we evaluated were higher in THS. We were able to detect trends towards a more liberal use of organ support, especially RRT, in SHI. ICU mortality was higher in SHI even after adjustment for confounders, while 30-day mortality showed no difference. There was a relatively consistent trend towards excess mortality in poorer SHI systems, which could be interpreted as there 
Table 1 Baseline characteristics of the cohort

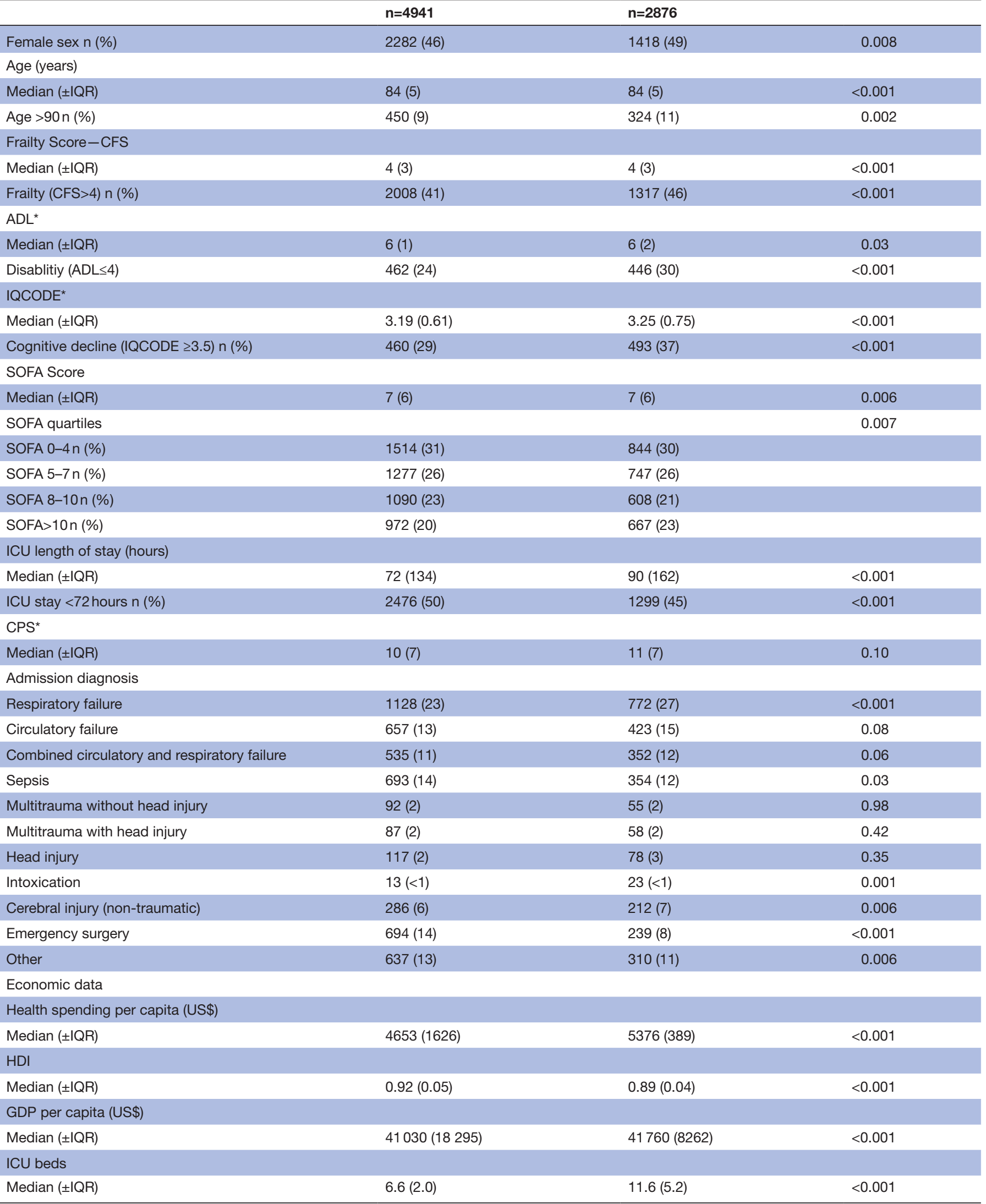

${ }^{*}$ Only available in VIP2 study.

ADL, activities of daily living; CFS, Clinical Frailty Scale; CPS, Co-morbidity and Polypharmacy Score; GDP, gross domestic product; HDI, human development index; ICU, intensive care unit; IQCODE, Informant Questionnaire on Cognitive Decline in the Elderly; SHI, social heath insurance system; SOFA, Sequential Organ Failure Assessment; THS, tax-based health service. 


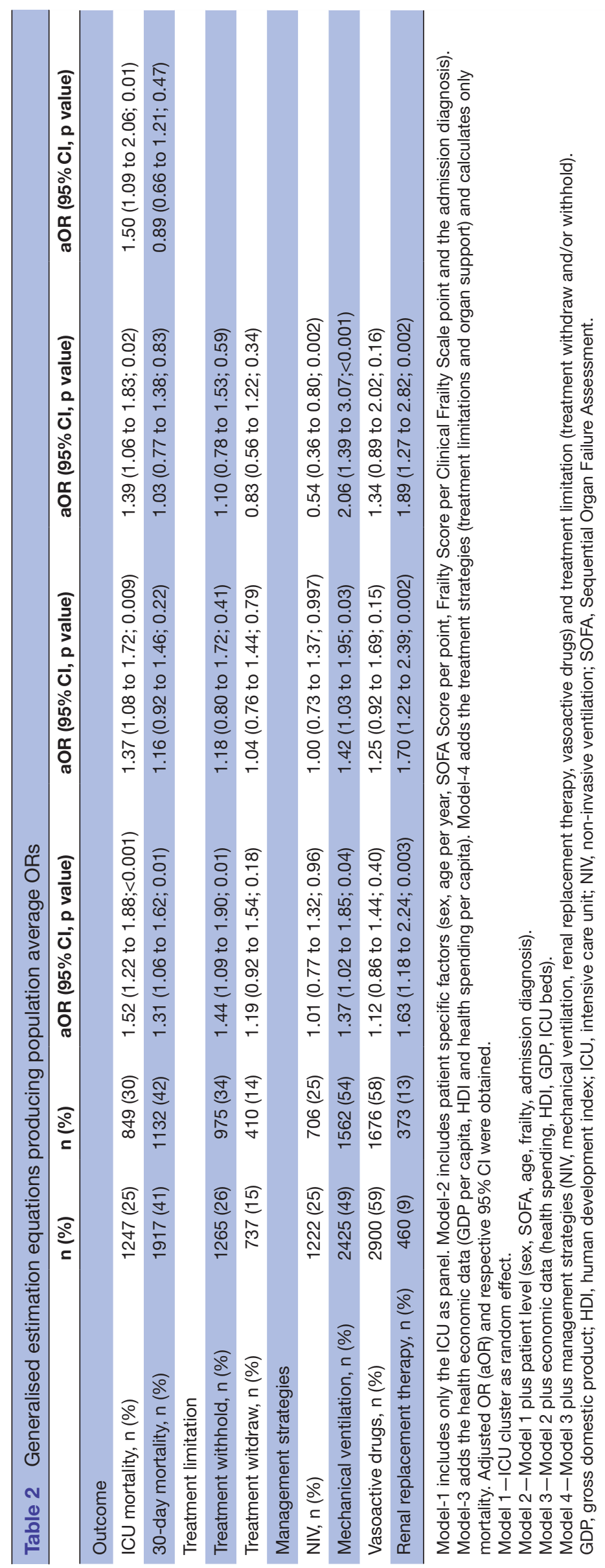


being an advantage in having a THS system in precarious settings where there are limited resources.

\section{Baseline risk distribution in SHI versus THS}

We interpret our findings that patients admitted to ICUs in SHI were older, frailer and more frequently suffered from cognitive impairment, as perhaps suggesting a more liberal admission policy in SHI. Intensivists in THS might need to apply a more stringent and strict triage criterion prior to ICU admission, as SHI had a higher number of ICU beds per capita. While in the THS, the allocation of resources is primarily centralised and, for example, based on quality-adjusted life year for specific procedures, in the SHI there is a coexistence of public and private ownership of hospitals. ${ }^{17}$ This gives rise to two possible explanations of the differences observed. First, the coexistence of public and private providers could lead to an excess (from the THS point of view) of poorly evidence-based healthcare interventions for economic reasons resulting in the wrong incentives for patient care. Second, the focus on financial constraints and resulting therapeutic and equipment limitations in the THS (from the SHI point of view) could lead to a restriction on admission and treatment, especially to subgroups of patients (such as the elderly). The verification of one of these two considerations is beyond the scope of this paper.

\section{Organ support and management in SHI versus THS}

The rates of RRT were consistently higher in SHI, but this broader application of organ support did not translate into a superior 30-day mortality compared with the more restrictive approach in THS. In our opinion, this could be interpreted as an indication of a more resource-efficient approach to patient care in THS. That this, presumably more economically favourable strategy, resulted in no detriment to patient outcome is interesting and potentially thesis generating.

The decision to restrict treatment based on a predicted individual prognosis is not an easy clinical task, even in older, critically ill patients. ${ }^{32}{ }^{33}$ We observed a trend towards more therapy limitation in SHI systems in the unadjusted analysis, but this signal disappeared after adjustment for health economic data. This signal could also have been interpreted as an excess of ICU beds in SHI. If one assumes that people in THS and SHI systems are of the same age with similar severity of illness, an increase in treatment goal limitations in SHI systems could indicate an overly liberal allocation of intensive care resources, especially when the outcomes are similar. It could then be assumed that patients with limitations on ceilings of care in the THS are not primarily treated in intensive care (and thus in a resource-saving manner).

\section{Mortality analysis}

The trend we have observed towards ICU excess mortality in SHI would also fit this explanation but could also be interpreted as an indication of worse quality of care in SHI. We, however, interpret this trend towards higher
ICU mortality in SHI systems as the result of a more liberal admissions policy due to the increased availability of ICU beds. This interpretation is supported by the fact that in the ICU mortality analysis stratified according to the SOFA Score (figure 4), excess mortality in the SHI was primarily detected in the highest quartile (SOFA $>10)$ this quartile is also overrepresented in the SHI $(23 \%$ vs $20 \%$ ). This could be due to a higher rate of 'futile' admissions, which were a priori not associated with clinical benefit. In other words, selection and triage, both by no means an easy task, in the THS may take place prior to ICU admission and in SHI during the ICU admission. ${ }^{6} 34$ We are, however, aware, that triage is not only a clinical but also an ethical challenge. Interestingly, the THS showed a trend towards higher rates of 'short-term' ICU stays (arbitrary cut-off at 72 hours). Again, this finding can be interpreted in a number of ways. On the one hand, this could primarily reflect the overall lower (and thus more resource efficient) duration of ICU stays in the THS. On the other hand, it could reflect a higher rate of 'ICU trials', that is, admissions to ICUs with the rationale to try a curative therapy trial for two to 2-3 days. At this point, the prognosis is re-evaluated, and if continuing the current treatment is deemed futile, there is a change in the goal of therapy and the patient is discharged from ICUs to receive ongoing care on a normal ward. ${ }^{35}$

After careful adjustment for possible confounders, we did not observe differences in the 30-day mortality. Why the better survival data at the time of ICU discharge in the THS do not translate into better outcomes at 30 days is beyond the scope of the present study. It could reflect different care for older patients in the THS (for example, because fewer geriatric or rehabilitation medical resources are available). If one accepted our considerations from above regarding triage, the THS may ultimately fail to translate the initially better patient selection into better long-term outcomes. This could underline the importance of geriatric treatment, especially after survival of an acute intensive care event. Intensive care certainly contributes to survival of the acute event, but only specialist geriatric treatment and rehabilitation might be able to translate this into better long-term outcomes. We can only speculate at this point about the morbidity rate, which is likely to also benefit from specialist geriatric care and rehabilitation. ${ }^{36}$

The pronounced increase in mortality from $27 \%$ on ICU discharge to $41 \%$ at 30 days could reflect the high well documented known mortality of older, critically ill patients. ${ }^{2}$ Systematic factors such, as national healthcare frameworks, or even patient-specific treatment strategies and therapy concepts could become less relevant in a group of very old patients as the age-associated mortality inherent in humans and the observed mortality could simply be an expression of the natural dying process.

\section{Sensitivity analyses}

In the sensitivity analysis, there was a signal that patients with a shorter length of stay had a higher mortality in SHI 
ICUs. Therefore, although in SHI hospitals more patients are admitted to ICU, they die relatively quickly. One possible explanation for this is that in THS ICUs these patients are never admitted, as when triaged for admission to ICU they are deemed unsuitable and therefore palliated on the wards.

There was a trend towards higher 30-day mortality, in the sensitivity analyses, in countries with lower GDP, lower HDI and lower numbers of ICU beds available in the SHI. The relatively consistent trend towards excess mortality in lower GDP SHI could be an expression of the relative superiority of a THS in settings with limited resources. Future public health studies could test this hypothesis, as it has potential consequences, for example, in assisting developing countries (with limited resources) that are building a new health system.

\section{Limitations}

This retrospective, post hoc study has several limitations. First, we are aware that the division between THS and SHI is an over-simplification and that mixed systems exist, especially in some countries such as Austria and Portugal. Further, we categorised the countries into SHI versus THS, but there may be country-specific and even site-specific differences within the two health systems. We have shown these differences for the primary and secondary endpoints in the online supplemental tables. These differences are presented in a descriptive manner as the absolute numbers in the countries are relatively low and not suitable for a formal statistical analysis. Other national or local factors that could influence our results are religious/cultural differences and expectations of family members. Unfortunately, we do not have any data on these potential confounders. Ultimately, we believe that the division into primarily directly tax-financed systems with strong state control (THS) or indirectly financed social insurance systems (SHI) is justified.

Another limitation is the potential selection bias. The 30-day endpoint was not available for all patients, which may have led to a selection bias. Furthermore, we have no specific information on local, national or inbuilt admission algorithms. For example, patients treated in SHI systems on ICUs (and triaged in the course of an ICU trial) may well be treated in THS intermediate care units not primarily managed by intensive care physicians and thus not included in the study data, which could also lead to selection bias.

Furthermore, in some areas our data lacks granularity. There are no data on functional capacity and morbidity, or management (discharge to home or institution), and/ or staffing ratios. Also, no data are available on the characteristics or absolute or relative frequencies of patients refused ICU admission. Despite this, we do have data on the baseline frailty and functional capacity for a significant number of critically ill patients and we think that our results add a novel insight into the differences between public healthcare systems.
Lastly, we are well aware of the limitations of sensitivity and subgroup analyses, which limit the generalisability of the conclusions drawn (figures 1-3). We chose to report these results to help generate ideas for future public health analyses. Despite all the limitations we consider our analysis to be a solid foundation for further studies comparing ICU management and its outcomes in both the THS and SHI healthcare settings.

\section{Conclusion}

To conclude, the adjusted 30-day mortality was similar in both systems. Patients in SHI were older, sicker and frailer which could be interpreted as a sign of a more liberal admission policy in SHI. We believe that the observed trend towards ICU excess mortality in SHI results mainly from a more liberal admission policy and an increased use of treatment limitations.

\section{Author affiliations}

${ }^{1}$ Department of Anaesthesiology, Perioperative Medicine and Intensive Care Medicine, Paracelsus Medical University Salzburg, Salzburg, Austria

${ }^{2}$ Center for Public Health and Healthcare Research, Paracelsus Medical University Salzburg, Salzburg, Austria

${ }^{3}$ Department of Medical Intensive Care, Hadassah University Medical Center, Jerusalem, Israel

${ }^{4}$ Division of Cardiology, Pulmonology, and Vascular Medicine, University Hospital Dusseldorf, Dusseldorf, Germany

${ }^{5}$ General Intensive Care, Hadassah Medical Center, Jerusalem, Israel

${ }^{6}$ service de réanimation médicale, Hôpital Saint-Antoine, Paris, France

${ }^{7}$ Depatment of Intensive Care Medicine, Autonomous University of Barcelona, Sabadell, Catalonia, Spain

${ }^{8}$ Department of Anaesthesia, Humanitas University, Milan, Italy

${ }^{9}$ Critical Care Medicine, Mater Misericordiae University Hospital, Dublin, Ireland

${ }^{10}$ Department of Intensive Care, UCINC, Hospital de São José, Centro Hospitalar de Lisboa Central, EPE, Lisbon, Portugal

${ }^{11}$ Department of Intensive Care, University of Ghent, Ghent, Belgium

${ }^{12}$ Department of Acute Medicine, Geneva University Hospitals, Geneve, Switzerland

${ }^{13}$ Department of Intensive Care and Perioperative Medicine, Jagiellonian University Medical College, Krakow, Poland

${ }^{14}$ General Intensive Care, Research Lead Critical Care Directorate St George's Hospital, London, UK

${ }^{15}$ Department of Medicine and Health Sciences, Faculty of Health Sciences, Linköping University, Division of Cardiovascular Medicine, Linköping, Sweden

${ }^{16}$ Department of Cardiothoracic Anaesthesia and Intensive Care, University Hospital, Linköping, Sweden

${ }^{17}$ Intensive Care Medicine, Inselspital, Bern University Hospital, Bern, Switzerland

${ }^{18}$ Division o Intensive Care and Emergency Medicine, Dept. Medicine, Medizinische Universitat Innsbruck, Innsbruck, Tirol, Austria

${ }^{19}$ Department of Intensive Care, Aarhus Universitet, Aarhus, Denmark

${ }^{20}$ Department of Critical Care, General University Hospital of Larissa, Larissa,

Thessaly, Greece

${ }^{21}$ Department of Intensive Care Medicine, Utrecht University, Utrecht, The Netherlands

${ }^{22}$ Service de Réanimation, Service de Réanimation Médicale Hôpital Saint-Antoine,

Paris, France

${ }^{23}$ Department of Anesthesia and Intensive Care, Haukeland University Hospital, Bergen, Norway

Collaborators VIP2 study group: Michael Joannidis, Philipp Eller, Raimund Helbok, René Schmutz, Joke Nollet, Nikolaas de Neve, Pieter De Buysscher, Sandra Oeyen, Walter Swinnen, Marijana Mikačić, Anders Bastiansen, Andreas Husted, Bård E S Dahle, Christine Cramer, Christoffer Sølling, Dorthe Ørsnes, Jakob Edelberg Thomsen, Jonas Juul Pedersen, Mathilde Hummelmose Enevoldsen, Thomas Elkmann, Agnieszka Kubisz-Pudelko, Alan Pope, Amy Collins, Ashok S Raj, Carole Boulanger, Christian Frey, Ciaran Hart, Clare Bolger, Dominic Spray, Georgina Randell, Helder Filipe, Ingeborg D Welters, Irina Grecu, Jane Evans, Jason Cupitt, 
Jenny Lord, Jeremy Henning, Joanne Jones, Jonathan Ball, Julie North, Kiran Salaunkey, Laura Ortiz-Ruiz De Gordoa, Louise Bell, Madhu Balasubramaniam, Marcela Vizcaychipi, Maria Faulkner, McDonald Mupudzi, Megan Lea-Hagerty, Michael Reay, Michael Spivey, Nicholas Love, Nick Spittle Nick Spittle, Nigel White, Patricia Williams, Patrick Morgan, Phillipa Wakefield, Rachel Savine, Reni Jacob, Richard Innes, Ritoo Kapoor, Sally Humphreys, Steve Rose, Susan Dowling, Susannah Leaver, Tarkeshwari Mane, Tom Lawton, Vongayi Ogbeide, Waqas Khaliq, Yolanda Baird, Antoine Romen, Arnaud Galbois, Bertrand Guidet, Christophe Vinsonneau, Cyril Charron, Didier Thevenin, Emmanuel Guerot, Guillaume Besch, Guillaume Savary, Hervé Mentec, Jean-Luc Chagnon, Jean-Philippe Rigaud, JeanPierre Quenot, Jeremy Castaneray, Jérémy Rosman, Julien Maizel, Kelly Tiercelet, Lucie Vettoretti, Maud Mousset Hovaere, Messika Messika, Michel Djibré, Nathalie Rolin, Philippe Burtin, Pierre Garcon, Saad Nseir, Xavier Valette, Christian Rabe, Eberhard Barth, Henning Ebelt, Kristina Fuest, Marcus Franz, Michael Horacek, Michael Schuster, Patrick Meybohm, Raphael Romano Bruno, Sebastian Allgäuer, Simon Dubler, Stefan J Schaller, Stefan Schering, Stephan Steiner, Thorben Dieck, Tim Rahmel, Tobias Graf, Anastasia Koutsikou, Aristeidis Vakalos, Bogdan Raitsiou, Elli Niki Flioni, Evangelia Neou, Fotios Tsimpoukas, Georgios Papathanakos, Giorgos Marinakis, loannis Koutsodimitropoulos, Kounougeri Aikaterini, Nikoletta Rovina, Stylliani Kourelea, Tasioudis Polychronis, Vasiiios Zidianakis, Vryza Konstantinia, Zoi Aidoni, Brian Marsh, Catherine Motherway, Chris Read, Ignacio Martin-Loeches, Andrea Neville Cracchiolo, Aristide Morigi, Italo Calamai, Stefania Brusa, Ahmed Elhadi, Ahmed Tarek, Ala Khaled, Hazem Ahmed, Wesal Ali Belkhair, Alexander D Cornet, Diederik Gommers, Dylan de Lange, Eva van Boven, Jasper Haringman, Lenneke Haas, Lettie van den Berg, Oscar Hoiting, Peter de Jager, Rik T Gerritsen, Tom Dormans, Willem Dieperink, Alena Breidablik Alena Breidablik, Anita Slapgard, Anne-Karin Rime, Bente Jannestad, Britt Sjøbøe, Eva Rice, Finn H Andersen, Hans Frank Strietzel, Jan Peter Jensen, Jørund Langørgen, Kirsti Tøien, Kristian Strand, Michael Hahn, Pål Klepstad, Aleksandra Biernacka, Anna Kluzik, Bartosz Kudlinski, Dariusz Maciejewski, Dorota Studzińska, Hubert Hymczak, Jan Stefaniak, Joanna Solek-Pastuszka, Joanna Zorska, Katarzyna Cwyl, Lukasz J Krzych, Maciej Zukowski, Małgorzata Lipińska-Gediga, Marek Pietruszko, Mariusz Piechota, Marta Serwa, Miroslaw Czuczwar, Mirosław Ziętkiewicz, Natalia Kozera, Paweł Nasiłowski, Paweł Sendur, Paweł Zatorski, Piotr Galkin, Ryszard Gawda, Urszula Kościuczuk, Waldemar Cyrankiewicz, Wojciech Gola, Alexandre Fernandes Pinto, Ana Margarida Fernandes, Ana Rita Santos, Cristina Sousa, Inês Barros, Isabel Amorim Ferreira, Jacobo Bacariza Blanco, João Teles Carvalho, Jose Maia, Nuno Candeias, Nuno Catorze, Vladislav Belskiy, Africa Lores, Angela Prado Mira, Catia Cilloniz, David Perez-Torres, Emilio Maseda, Enver Rodriguez, Estefania Prol-Silva, Gaspar Eixarch, Gemma Gomà, Gerardo Aguilar, Gonzalo Navarro Velasco, Marián Irazábal Jaimes, Mercedes Ibarz Villamayor, Noemí Llamas Fernández, Patricia Jimeno Cubero, Sonia López-Cuenca, Teresa Tomasa, Anders Sjöqvist, Camilla Brorsson, Fredrik Schiöler, Henrik Westberg, Jessica Nauska, Joakim Sivik, Johan Berkius, Karin Kleiven Thiringer, Lina De Geer, Sten Walther, Filippo Boroli, Joerg C Schefold, Leila Hergafi, Philippe Eckert, Ismail Yıldı, Ihor Yovenko, Yuriy Nalapko, Yuriy Nalapko, Richard Pugh

Contributors BW, CJ and MB conceived the presented idea. BW developed the theory and performed the computations. RRB, SB, MK, SS, PVvH, AB, AA, MC, BM, RM, SO, BBP, WS, SL, SMW, JCS, MJ, JF, TZ, DdL, BG, HF and CJ contributed to the final version of the manuscript. CJ supervised the project. SL edited English language. CJ, HF and MB verified the analytical methods.

Funding The authors have not declared a specific grant for this research from any funding agency in the public, commercial or not-for-profit sectors.

Competing interests None declared.

Patient consent for publication Not required.

Ethics approval Each study site obtained institutional research ethics board approval.

Provenance and peer review Not commissioned; externally peer reviewed.

Data availability statement Data are available upon reasonable request. Data are available upon reasonable request.

Supplemental material This content has been supplied by the author(s). It has not been vetted by BMJ Publishing Group Limited (BMJ) and may not have been peer-reviewed. Any opinions or recommendations discussed are solely those of the author(s) and are not endorsed by BMJ. BMJ disclaims all liability and responsibility arising from any reliance placed on the content. Where the content includes any translated material, BMJ does not warrant the accuracy and reliability of the translations (including but not limited to local regulations, clinical guidelines, terminology, drug names and drug dosages), and is not responsible for any error and/or omissions arising from translation and adaptation or otherwise.
Open access This is an open access article distributed in accordance with the Creative Commons Attribution Non Commercial (CC BY-NC 4.0) license, which permits others to distribute, remix, adapt, build upon this work non-commercially, and license their derivative works on different terms, provided the original work is properly cited, appropriate credit is given, any changes made indicated, and the use is non-commercial. See: http://creativecommons.org/licenses/by-nc/4.0/.

\section{ORCID iDs}

Bernhard Wernly http://orcid.org/0000-0003-4024-0220

Raphael Romano Bruno http://orcid.org/0000-0003-3776-3530

Malte Kelm http://orcid.org/0000-0001-5834-2757

Wojciech Szczeklik http://orcid.org/0000-0002-1349-1123

\section{REFERENCES}

1 Flaatten H, Garrouste-Orgeas M. The very old ICU patient: a neverending story. Intensive Care Med 2015;41:1996-8.

2 Boumendil A, Angus DC, Guitonneau A-L, et al. Variability of intensive care admission decisions for the very elderly. PLoS One 2012;7:e34387.

3 Leblanc G, Boumendil A, Guidet B. Ten things to know about critically ill elderly patients. Intensive Care Med 2017;43:217-9.

4 Boumendil A, Somme D, Garrouste-Orgeas M, et al. Should elderly patients be admitted to the intensive care unit? Intensive Care Med 2007;33:1252.

5 Guidet B, de Lange DW, Flaatten H. Should this elderly patient be admitted to the ICU? Intensive Care Med 2018;44:1926-8.

6 van Heerden PV, Sviri S, Beil M, et al. The wave of very old people in the intensive care unit-A challenge in decision-making. $J$ Crit Care 2020;60:290-3.

7 Hollinger A, Gayat E, Féliot E, et al. Gender and survival of critically ill patients: results from the FROG-ICU study. Ann Intensive Care 2019;9:43.

8 Block L, Petzold M, Syrous AN, et al. Age, saps 3 and female sex are associated with decisions to withdraw or withhold intensive care. Acta Anaesthesiol Scand 2019;63:1210-5.

9 Jung C, Wernly B, Muessig JM, et al. A comparison of very old patients admitted to intensive care unit after acute versus elective surgery or intervention. J Crit Care 2019;52:141-8.

10 Ferrante LE, Pisani MA, Murphy TE, et al. Functional trajectories among older persons before and after critical illness. JAMA Intern Med 2015;175:523-9.

11 Muessig JM, Nia AM, Masyuk M, et al. Clinical frailty scale (CFS) reliably stratifies octogenarians in German ICUs: a multicentre prospective cohort study. BMC Geriatr 2018;18:162.

12 Bruno RR, Wernly $\mathrm{B}$, Flaatten $\mathrm{H}$, et al. The hospital frailty risk score is of limited value in intensive care unit patients. Crit Care 2019;23:239.

13 Canevelli M, Raganato R, Remiddi F, et al. Counting deficits or diseases? the agreement between frailty and multimorbidity in subjects with cognitive disturbances. Aging Clin Exp Res 2020;32:179-82.

14 Flaatten H, De Lange DW, Morandi A, et al. The impact of frailty on ICU and 30-day mortality and the level of care in very elderly patients ( $\geq 80$ years). Intensive Care Med 2017;43:1820-8.

15 Delnoij DMJ. Bismarck or Beveridge: primary care matters. Eur J Public Health 2013;23:349.

16 Gaeta M, Campanella F, Capasso L, et al. An overview of different health indicators used in the European health systems. J Prev Med Hyg 2017;58:E114-20.

17 van der Zee J, Kroneman MW. Bismarck or Beveridge: a beauty contest between dinosaurs. BMC Health Serv Res 2007;7:94.

18 Herzlinger RE, Parsa-Parsi R. Consumer-Driven health care: lessons from Switzerland. JAMA 2004;292:1213-20.

19 Health care systems in the European Union countries. Available: https://www.mscbs.gob.es/estadEstudios/estadisticas/docs/ presentacion en.pdf

20 Busse R, Schreyögg J, Gericke C. Analyzing changes in health financing arrangements in high-income countries a comprehensive framework approach. 1. Articles in other Journals and Books, 2007.

21 Kulesher RR, Elizabeth Forrestal E, Forrestal E. International models of health systems financing. J Hosp Adm 2014;3:127-39.

22 Wagstaff A. Social health insurance vs. tax-financed health systemsevidence from the OECD: the world bank, 2009.

23 Joël M-E, Dufour-Kippelen S. Financing systems of care for older persons in Europe. Aging Clin Exp Res 2002;14:293-9.

24 Guidet B, de Lange DW, Boumendil A, et al. The contribution of frailty, cognition, activity of daily life and comorbidities on outcome in 
acutely admitted patients over 80 years in European ICUs: the VIP2 study. Intensive Care Med 2020;46:57-69.

25 Rockwood K, Song X, MacKnight C, et al. A global clinical measure of fitness and frailty in elderly people. CMAJ 2005;173:489-95.

26 Jorm AF, Jacomb PA. The informant questionnaire on cognitive decline in the elderly (IQCODE): socio-demographic correlates, reliability, validity and some norms. Psychol Med 1989;19:1015-22.

27 Katz S. Assessing self-maintenance: activities of daily living, mobility, and instrumental activities of daily living. $J$ Am Geriatr Soc 1983;31:721-7.

28 International-Monetary-Fund. World economic outlook reports, 2019. Available: https://www.imf.org/en/publications/weo

29 UNDP. Human development report 2019, 2019.

30 OECD. Health at a glance, 2019. Available: https://data.oecd.org/ healthres/health-spending.htm

31 Rhodes A, Ferdinande P, Flaatten $\mathrm{H}$, et al. The variability of critical care bed numbers in Europe. Intensive Care Med 2012;38:1647-53.
32 Guidet B, Flaatten $\mathrm{H}$, Boumendil A, et al. Withholding or withdrawing of life-sustaining therapy in older adults ( $\geq 80$ years) admitted to the intensive care unit. Intensive Care Med 2018;44:1027-38.

33 Nih consensus conference. diagnosis and treatment of depression in late life. JAMA 1992;268:1018-24.

34 Flaatten $\mathrm{H}$, Van Heerden $\mathrm{V}$, Jung $\mathrm{C}$, et al. The good, the bad and the ugly: pandemic priority decisions and triage. J Med Ethics 2020. doi:10.1136/medethics-2020-106489. [Epub ahead of print: 10 Jun 2020] (published Online First: 2020/06/12).

35 Lecuyer L, Chevret S, Thiery G, et al. The ICU trial: a new admission policy for cancer patients requiring mechanical ventilation. Crit Care Med 2007;35:808-14.

36 Cuthbertson BH, Goddard SL, Lorencatto F, et al. Barriers and facilitators to early rehabilitation in the ICU: a theory driven Delphi study. Crit Care Med 2020;48:e1171-8. 